\title{
PROBLEMATIZANDO A QUEIXA ESCOLAR: EFEITOS DOS DISCURSOS PSI NOS FAMILIARES DOS ALUNOS EM SITUAÇÃO DE INSUCESSO ESCOLAR
}

\author{
PROBLEMATIZING THE SCHOOL COMPLAIN: EFFECTS FROM PSI DISCOURSES \\ IN STUDENTS RELATIVES IN SCHOOL UNSUCCESSFUL SITUATION
}

PROBLEMATIZAR LA QUEJA ESCOLAR: EFECTOS DE LOS DISCURSOS PSI EM LOS
FAMILIARES DE ESTUDIANTES EN SITUACIÓN DE FRACASO ESCOLAR

\section{Célia Ratusniak* celia5696@hotmail.com \\ Carla Clauber da Silva** carlaclauber@hotmail.com}

Thaymã Sznycer

thaymacas@yahoo.com

REVISTA PEDAGÓGICA

Revista do Programa de Pós-graduação em Educação da Unochapecó | ISSN 1984-1566 Universidade Comunitária da Região de Chapecó | Chapecó-SC, Brasil Como referenciar este artigo: RATUSNIAK, C.; SILVA, C. C.; SZNYCER, T. Problematizando a queixa escolar: efeitos dos discursos PSI nos familiares dos alunos em situação de insucesso escolar. Revista Pedagógica, Chapecó, v. 19, n. 40, p. 286-301, jan./abr. 2017. DOI: http://dx.doi.org/10.22196/rp.v19i40.3754

RESUMO: Este artigo é resultado do projeto de extensão Atendimento à queixa escolar-possibilidades de intervenções em Psicologia Escolar para alunos com diagnóstico ou suspeita de TDAH, Transtorno de Conduta ou com fracasso escolar, vinculado ao Núcleo de Serviços em Psicologia da Universidade do Contestado (UnC). Problematiza os efeitos do discurso que patologiza as dificuldades de aprendizagem, subjetivando os familiares, que passam a ver seus filhos como sujeitos doentes. Discute a figura do aluno com problemas de aprendizagem e as (im)possibilidades oferecidas pelas ciências $p s i$, que contribuem para a sua demarcação no espaço da anormalidade, individualizando as causas do não aprender. Como conclusões, evidenciamos a relevância de deslocar a compreensão da queixa escolar, rompendo com a medicalização e a culpabilização dos estudantes e suas famílias pelo fracasso escolar, deslocamento esse que permite a criação de espaços de resistência que constroem novas práticas em Psicologia Escolar.

Palavras-chave:Queixa Escolar. Psicologia Escolar. Anormalidade.Insucesso Escolar.Famílias.

ABSTRACT: This paper is the result of the extension project Assistance to school's complain - possibilities of School Psychology intervention to students with diagnosed or suspect of ADHD, Conduct Disorder or school failure, linked to Center of Psychology Services of Universidade do Contestado (UnC). Problematize the effects of discourse that pathologises the difficulties of learning, subjecting the relatives that began to see their children as sicked subjects. Discusses the figure of a student with learning problems and the (im)possibilities delivered by psi sciences, that helps to a demarcation in the abnormality space, individualizing the causes of not learning. As conclusions, we evidence the relevance of dislocate the comprehension of school complain, breaking with the families and student's medicalization and scapegoating by the school failure, dislocation this will allow the creation of resistance spaces that built new practices in School Psychology.

Keywords: School Complain. School Psychology. Abnormality. School Failure. Families.

RESUMEN: Este articulo es resultado del proyecto de extensión Asistencia a la queja escolar - posibilidades de intervenciones en Psicología Escolar para estudiantes con diagnosticoo sospecha de TDAH, Trastorno de la Conducta o fracaso escolar, del Nucleo de Servicios en Psicología de la Universidade do Contestado (UnC). Analizan los efectos del discurso que patologiza las dificultades de aprendizaje, subjetivando los familiares que empiezan a ver sus hijos como sujetos enfermos. Se discute la figura del estudiante con problemas de aprendizaje y las (im)posibilidades ofrecidas por las ciencias $p s i$, que contribuye para su demarcación en el espacio de la anormalidad, individualizando las causas de no aprender. Como conclusiones, se evidencia la relevancia de desplazar la comprensión de la queja escolar, rompiendo con la medicalización e la culpabilidad de los estudiantes y sus familia por lo fracaso escolar, desplazamiento este que posibilita la creación de espacios de resistencia que construyen nuevas practicas en Psicología Escolar.

Palabras-clave: Queja Escola. Psicología Escolar. Anormalidad. Fracaso Escolar. Familias. 


\footnotetext{
* Doutoranda em Educação pela UFPR. Membro dos grupos de pesquisa A Constituição do Sujeito na Contemporaneidade, e do LABIN - Laboratório de Investigação em Corpo, Gênero e Subjetividades na Educação, ambos cadastrado no CNPq. Professora da Universidade do Contestado, campus de Porto União/SC.

** Pesquisadora do Núcleo de Pesquisa em arte e Educação: NUPAE na Universidade da Região de Joinville. Santa Catarina, Joinville. Brasil.
}

\section{INTRODUÇÃO}

Esse artigo tem como objetivo problematizar a produção da figura do aluno com dificuldades escolares por meio do discurso produzido pelo dispositivo pedagógico, a partir do trabalho com grupos realizados com os seus familiares. Trata-se de uma ação do Núcleo de Serviços e Psicologia vinculado ao Curso de Graduação em Psicologia da Universidade do Contestado (UnC), onde são desenvolvidos projetos de extensão de caráter comunitário. Nesse artigo, compartilhamos problematizações acerca do projeto: Atendimento à queixa escolar - possibilidades de intervenções em Psicologia Escolar para alunos com diagnóstico ou suspeita de TDAH, Transtorno de conduta ou com história de fracasso escolar. É um projeto que iniciou em 2013, estendendo-se até 2016, e que tinha como objetivo principal oferecer um espaço de intervenção à queixa escolar e de reflexão sobre os efeitos da patologização e da medicalização dos estudantes que estão em situação de insucesso escolar.

Neste artigo, inicialmente, contextualizamos o trabalho no Núcleo de Serviços de Psicologia, especificamente nesse projeto de extensão, procurando evidenciar que o eixo central é o diálogo, a reflexão e a interação com os sujeitos envolvidos. Posteriormente, problematizamos a figura do aluno com problemas de aprendizagem e as (im) possibilidades oferecidas pelas ciências psi, que contribuem com certos discursos que demarcam seu lugar no espaço da anormalidade, individualizando as causas do não aprender, depositando nos estudantes e em suas condições de existência as causas de suas queixas escolares. Evidenciamos a relevância de deslocar a compreensão da queixa escolar, rompendo com a medicalização e a culpabilização dos estudantes pelo fracasso escolar, deslocamento esse que possibilita construir novas práticas a partir de outras compreensões acerca da queixa escolar.

Este estudo problematiza os efeitos do discurso pedagógico e psicológico patologizantes nas percepções que os familiares têm acerca de suas filhas e seus filhos, produzindo sujeitos doentes, subjetivados pelos distúrbios e/ ou transtornos de aprendizagem.Finalizando, o trabalho aponta para a necessidade de abertura de espaços de resistência, onde esses discursos sejam problematizados por estudantes, familiares, professoras e pedagogas, despatologizando a não aprendizagem.

\section{NÚCLEO DE SERVIÇOS E PSICOLOGIA: ESPAÇO DE INVESTIGAÇÃO E PROBLEMATIZAÇÃO DE SUAS PRÓPRIAS PRÁTICAS}

A queixa escolar é o maior motivo pelo qual alunos e alunas da rede pública procuram atendimento clínico 
no Núcleo de Serviços em Psicologia, onde o projeto de extensão tematizado por este artigo funcionou. Pesquisas realizadas nesse espaço feitas por Medeiros (2015) e Viana (2015) apontam que a psicoterapia individual não é eficaz nas situações de insucesso escolar. Medeiros (2015) analisou o desempenho acadêmico a partir da análise dos históricos escolares de estudantes que passaram por atendimento psicoterápico na Clínica-Escola, ligada ao Núcleo de Serviços em Psicologia, entre 2011 e 2016. Sua pesquisa revelou que apenas $5 \%$ apresentaram melhoria no seu rendimento; 68\% deles permaneceram com a média anual estável e $27 \%$ diminuíram sua média final. Viana analisou as altas e desistências de atendimentos clínicos de estudantes encaminhados por queixa escolar no mesmo Núcleo. Verificou-se que dos 150 alunos que passaram pela triagem psicológica, 71 deles apresentavam queixa escolar. Desses 71 alunos, 70 foram desligados do atendimento. As justificativas encontradas pela pesquisadora apontavam que $20 \%$ tiveram faltas consecutivas sem aviso prévio; $16 \%$ desistiram durante o ano; $15 \%$ desistiram no fim do ano; $13 \%$ agendaram atendimento, mas não compareceram; 7\% possuíam dificuldade de deslocamento; $3 \%$ já haviam iniciado atendimento com outro profissional e apenas $1 \%$ recebeu alta por melhoria nas queixas iniciais (VIANA, 2015).

O projeto de extensão tematizado nesse artigo tem como objetivo produzir outras práticas psicológicas para além da psicoterapia clínica, que desnaturalizem as justificativas do não aprender. Para tanto, procuramos construir espaços onde as nomeações e os lugares destinados aos alunos e alunas em situação de dificuldade de aprendizagem/ problemas de comportamento fossem ressignificados, fazendo emergir a figura daquele que pode aprender, desde que lhe sejam oferecidas as condições favoráveis.

Realizamos atividades semanais, que tiveram como objetivo criar um espaço de diálogo com grupos de familiares e com grupos de alunos com queixa escolar. Também viabilizamos espaços de discussão mensais com as escolas onde estes alunos e alunas estudavam, problematizando o fracasso escolar como produzido nas práticas escolares. Possibilitamos a criação de um lugar onde os sujeitos pudessem expressar as angústias em relação aos comportamentos inadequados e ao desempenho escolar destes estudantes, questionando as formas como as instituições contemporâneas, principalmente a escola e a Psicologia, vêm trabalhando com a diferença e com aqueles que questionam a forma como as relações de exclusão se estabelecem e se naturalizam na escola.

Por ser um projeto permanente, oferecemos a possibilidade de realização de horas complementares ao currículo para alunos dos cursos de Psicologia. Também foi um espaço para a realização de estágio Curricular Obrigatório em Psicologia Escolar. Alunos recém-formados também trabalharam, com o objetivo de fortalecer as práticas psicológicas na área escolar e educacional. Participaram do 
projeto 12 alunos do curso de Psicologia, três profissionais recém-formados, 30 alunos em situação de insucesso escolar, seus familiares, professores, pedagogos e diretores das escolas em que estudam O projeto também foi tema de quatro pesquisas acadêmicas. Possuíamos convênio com a Secretaria Municipal de Educação de Porto União desde 2013. Como resultado mais significativo, ressaltamos que todos os estudantes que por ele passaram melhoraram seu desempenho escolar.

\section{A INVENÇÃO DA FIGURA DO ALUNO COM DIFICULDADES DE APRENDIZAGEM}

A escola é uma instituição moderna, que surgiu no final do século XVII, simultaneamente aos asilos, quartéis, prisões e manicômios. As escolas são instituições disciplinares criadas para o controle e o governo da população, que tinham como objetivo docilizar os corpos e torná-los mais produtivos (FOUCAULT, 2009). A escola primária, destinada à educação das crianças, surgiu na Europa a partir da definição de um estatuto da infância, que foi constituído a partir de saberes sobre a infância e sobre as crianças.Essas passaram a ser estudadas, observadas, extraindo desses olhares padrões de comportamento que originaram a Psicologia do Desenvolvimento.

As primeiras escolas modernas europeias se tornaram os lugares onde se operavam tecnologias de controle e disciplinamento sobre o corpo das crianças e se transformaram em uma espécie de quarentena onde as crianças deveriam ficar confinadas durante toda a sua infância (VARELLA; ALVAREZ-URIA,1991). Cada infância tinha a escola que merecia, visto que para as crianças das classes operárias e camponesas eram destinadas às escolas de primeiras letras, que tinham como objetivo "[...] impor-lhes hábitos de limpeza, regularidade, compostura, obediência, diligência, respeito à autoridade, amor ao trabalho e espírito de poupança" (VARELLA; ALVAREZ-URIA, 1991, p. 37). Assim, a escola passou a ter a função de transformar a criança em aluno a partir da disciplinarização de seu corpo e do governo de sua alma, operando um processo de subjetivação intenso e cotidiano.

Para que se transformasse em aluno, era preciso fazer essa criança incorporar comportamentos, ideias e aprendizagens condizentes com o que é esperado para a sua etapa de escolarização e idade, ou seja, aquilo que está previsto na norma. Ela passa a ser regida pelas leis psicológicas do desenvolvimento - compostas de fases, níveis, estágios produzidas a partir dos estudos desenvolvidos pela Medicina, pela Psicologia e pela Pedagogia.

O bom aluno surgiu no discurso pedagógico moderno como aquele que é independente, responsável, aquele que, medindo muito bem tanto os seus atos e suas formas de comportamento, saberia sempre encontrar a melhor forma de se adaptar espontaneamente à vida escolar. Para 
que esses alunos sejam produzidos, instituiu-se toda uma tecnologia de controle dos corpos e de condução de condutas, de liberdades reguladas que permitem a regulação psicológica do eu (RAMOS DO Ó, 2007).

Junto com a figura do bom aluno, produziu-se a norma e com ela a figura do aluno com dificuldades de aprendizagem. Essas duas figuras foram criadas a partir do exame, ritualizado pela escola em um jogo de pergunta/resposta/ recompensa que reativa os mecanismos de constituição do saber em uma relação de poder específica (RAMOS DO Ó, 2007). O exame é realizado a partir do olhar que compara e analisa, em uma tecnologia de vigilância composta por testes, observações, exames clínicos, laboratoriais, de imagem, entrevistas, escalas, checklists, relatórios, observações, laudos, avaliações. São dispositivos que classificam e reclassificam os alunos, que marcam a distinção entre normalidade e anormalidade (VEIGA-NETO, 2001).

Foucault (2001) problematiza a genealogia da anomalia, apresentando a figura do incorrigível, para quem é preciso desenvolver técnicas diversificadas de correção para além daquelas utilizadas pela média da população. Segundo o filósofo francês:

[...] O que define o indivíduo a ser corrigido, portanto, é que ele é incorrigível. E, no entanto, paradoxalmente, o incorrigível, na medida em que é corrigível, requer um certo número de intervenções específicas em torno de si, sobre intervenções em relação às técnicas familiares e corriqueiras de educação e correção, isto é, uma nova tecnologia da reeducação, da sobrecorreção. (FOUCAULT, 2001, p. 73).

Essas tecnologias de correção surgiram no discurso pedagógico a partir dos experimentos de Jean Itard, médico francês, que no final do século XVIII desenvolveu todo um conhecimento a partir de um minucioso trabalho de observação e aplicação de técnicas pedagógicas na tentativa de humanização do menino Victor, conhecido como o Selvagem de Aveyron, produzindo um tratamento para o incorrigível.

A partir do século XX, iniciou-se uma expansão do interesse a respeito da deficiência mental leve pela Psicologia Científica e pela Medicina, desenvolvendo tratamentos que melhorassem as capacidades cognitivas afetadas, originando aquilo que mais tarde se chamaria de Educação Especial. A Medicina se ocupou em desenvolver tratamentos para esses sujeitos que nãopoderiam mais ser confinados. A Pedagogia produziu formas de estender o ensino a esses alunos, criando metodologias específicas e a Psicologia se encarregou de desenvolver estratégias e técnicas para medir as capacidades daqueles que não aprendiam no mesmo ritmo em comparação com os sujeitos normais (PESSOTTI, 1984).

Para Lopes e Fabris (2005), o que configura a posição de aluno com dificuldades de aprendizagem é um 
descompasso no tempo entre os alunos e os espaços destinados àqueles que não aprendem. Na escola, todo o tempo é esquadrilhado, e aqueles que se enquadram ou que cumprem as tarefas e aprendem nesse tempo estimado circulam pelos diversos espaços na escola, em um fluxo ascendente, regulado pelos bimestres, pelos anos e pelas etapas de escolarização. A promoção dos estudantes também é possibilitada pela média que se leva para resolver as atividades e pelo desempenho nas diversas provas de aprendizagem. Se cumprirem esse tempo médio, avançarão nos segmentos: ensino fundamental, médio, superior e pós-graduação.

O exame e a impossibilidade dos deslocamentos ocasionados pelo desempenho abaixo do esperado produzem discursos que marcam a posição do aluno como aquele com dificuldade de aprendizagem. Esses discursos fazem parte do dispositivo pedagógico, descrevendo as causas, classificando-os em distúrbios e transtornos como a dislexia, disgrafia, disortografia, Transtorno do Déficit de Atenção e Hiperatividade (TDAH), deficiência intelectual, Transtorno Opositivo Desafiador (TOD). Diagnosticam, justificando a não aprendizagem por problemas familiares, econômicos, dificuldades de socialização, de compreensão, de atenção, de concentração. Ganham força se apoiando nos discursos psicológicos, que através exames e testes detectam razões para a não aprendizagem ou para justificar a medicalização dos alunos (LOPES; FABRIS, 2005). Esses discursos individualizam a causas do não aprender, depositando nos estudantes e em suas condições de existência as causas de suas queixas escolares.

A dimensão da figura daquele que possui dificuldades de aprendizagens ganha espaço, totalizando esses estudantes, fazendo com que sejam identificados como problemáticos, doentes, desajustados, impedindo que outras formas de existência possam emergir para além da figura daquele que possui problemas de aprendizagem.

\section{A QUEIXA ESCOLAR E PSICOLOGIA ESCOLAR: DEMARCAÇÃO DE ESPAÇO DE ANORMALIDADE OU PRODUÇÃO DE DESLOCAMENTOS?}

Queixa escolar é uma demanda de trabalho originada nas instituições escolares, a partir de encaminhamentos para a Psicologia. Trautwein e Nébias (2006) conceituam como queixas escolares as dificuldades relacionadas ao rendimento dos alunos e ao comportamento inadequado, que originam solicitações de atendimento ou encaminhamentos para médicos, psicólogos ou psicopedagogos. Para Souza (2007a), a queixa escolar, na maioria das práticas psicológicas, é entendida como um problema de aprendizagem ou de comportamento de fundo emocional, detectado pelo olhar normalizador já no início do processo de escolarização. Originada por supostos conflitos internos ou resultado de problemas neurológicos, normalmente as causas 
apontadas estão no aluno ou em sua família, isentando-se o sistema escolar.

A Psicologia Escolar vem buscando novas formas para a intervenção na queixa escolar para além do atendimento clínico. As discussões advindas da década de 1980 passaram a redimensionar a tarefa da Psicologia, defendendo a necessidade de mudança nos referenciais teóricos para a compreensão das questões escolares. Esse movimento produziu um conjunto de práticas e de pesquisas que romperam com a culpabilização das crianças, adolescentes e suas famílias pelas dificuldades escolares, construindo assim novas formas de compreensão da queixa escolar (SOUZA, 2007b).

Esses deslocamentos produziram repercussões importantes na pesquisa em Psicologia Escolar, ressaltando a importância de problematizarmos os fenômenos educacionais a partir dos processos que acontecem no interior da escola. Para tanto, foi necessário encontrar modelos teórico-metodológicos que superassem a noção unilateral de adaptação da criança ao sistema escolar, produzindo outras formas de se fazer para a Psicologia no campo da educação (SOUZA, 2007b).

Problematizar as práticas escolares significa criar encontros para discutir como os fenômenos surgem, que situações originam comportamentos inadequados e que possibilidades de lidar com eles a escola pode produzir para além do encaminhamento. Encontros que podem produzir formas diferentes de se ensinar, construindo espaços cooperativos e colaborativos entre alunos e professores, valorizando as aprendizagens de todos e de cada um. Encontros que promovam diálogo entre profissionais da escola e familiares do aluno, que estreitem os laços de confiança e que permitam que a escola seja um lugar bom para todos aprenderem. Encontros que possibilitem, a partir de suas discussões, a elaboração de políticas públicas que permitam a existência de modos de ser diferentes na escola, e que estes não sejam patologizados ou psicologizados.

Nesse sentido, o projeto de extensão Atendimento à queixa escolar - possibilidades de intervenções em Psicologia Escolar para alunos com diagnóstico ou suspeita de TDAH ou de Transtorno de conduta ou com história de fracasso escolar se configura como um espaço de encontro. Leandrini e Saretta (2007) sugerem que o trabalho com grupos para pode ser uma boa estratégia para trabalhar a queixa escolar. Estes grupos têm como objetivo realizar uma aproximação entre estudantes/professoras/familiares, fortalecendo relações de respeito e o diálogo. Com esta aproximação, é possível desmistificar a figura autoritária imposta por aqueles que supostamente sabem sobre o outro, e que determinam como cada um deve ser. Os grupos também fazem com que o aluno saia do ambiente escolar, lugar em que muitas vezes é estigmatizado, podendo demonstrar outras formas de existência para além do aluno com problemas. Os grupos podem promover conversas nos 
casos em que a estigmatização tornou as relações improváveis.

Durante os quatro anos em que o projeto se desenvolveu, algumas regularidades eram percebidas nos discursos dos familiares sobre a posição de insucesso ocupada por suas filhas e filhos. Problematizaremos aqui as justificativas apresentadas, que mostram como o discurso pedagógico sobre o não aprender objetiva e subjetiva essas famílias. Para tanto, utilizaremos falas de três mães e de um pai, que participavam do projeto: Aparecida tem 32 anos, é auxiliar de cozinha, casada, mãe de duas filhas, e a sua filha mais nova(Joice)participa do grupo. Gabriela tem 34 anos, trabalha como servente, é separada, mãe de três filhos, e a sua filha mais nova (Laura)participa do grupo. Graciela tem 32 anos, "do lar", é casada, mãe de três filhos, e o seu filho mais novo (João) foi encaminhado por sua escola. Geraldo tem 52 anos, trabalha como autônomo em serviços gerais, tem um filho de 8 anos (José). As falas desses familiares serão transcritas em itálico, seguidas dos nomes fictícios que foram escolhidos por eles mesmos.

\subsection{Problematizações sobre a queixa escolar: deslocamentos da individualização do não aprender para a compreensão da falta de condições para ensinar}

As escolas possuem formas de organização que nem sempre privilegiam a aprendizagem dos alunos. A escolha de turmas no início do ano é um bom exemplo disso. Existem critérios que permitem que os professores mais antigos escolham as turmas, deixando para os menos experientes as salas de período de alfabetização ou turmas com problemas de aprendizagem e/ou de comportamento. Essa sistemática de distribuição acaba prejudicando os alunos com queixa escolar, pois poucas vezes as professoras que possuem maior conhecimento sobre os processos de aprendizagem e a experiência na organização do trabalho pedagógico escolherão trabalhar com estas turmas.

Outro exemplo de organização inadequada é a garantia de recuperação de conteúdos ao aluno em situação de dificuldade de aprendizagem, garantida pela Lei $n^{0}$ 9.394/96 - Lei de Diretrizes e Bases da Educação (LDB) (BRASIL, 1996). As escolas atendidas pelo projeto de extensão problematizado neste artigo possuem o Apoio Pedagógico, que é um programa de recuperação de conteúdos, que funciona em contraturno escolar. Os alunos em situação de insucesso escolar são encaminhados para esse programa, com a promessa de que, com um tempo maior e um atendimento diferenciado, aprenderão. Mas isso não aconteceu. A filha de Aparecida frequentava esse espaço por dois anos, sem ter aprendido a ler e escrever. Isso fez com que inventasse constantemente desculpas para não ir ao Apoio Pedagógico: "Ela pede para ficar em casa, não gosta de ir ao reforço. Ela sempre passa a conversa e eu caio" (Aparecida). Com o 
1 O Projeto Escola de Pais: "Tem como objetivo auxiliar a família na valorização do núcleo familiar como fonte geradora de princípios e valores. Para realização do projeto, conta-se com a participação de voluntários dos diversos segmentos da sociedade que vão até a escola e desenvolvem temas como: relacionamento familiar, resgate de valores e de limites, prevenção às drogas e à violência, responsabilidade dos pais e da escola, a importância da autoestima para o desenvolvimento da criança, Deus na família, motivação e qualidade de vida (PME, 2009, p. 151, grifos nossos). filho de Ezequiel, não é diferente: "Ele me engana que não tem aula só para ficar em casa assistindo desenho". O sentimento de frustração e incompetência faz com que esses alunos não queiram ir para a escola: "A professora disse que explica, explica, e ela [sua filha] não entende" (Gabriela). As problematizações realizadas durante os grupos foram realizadas no sentido de mostrar que esses estudantes, com a recusa de ir ao contra turno de reforço, estão informando que o Apoio Pedagógico não os colocou em situação de aprendizagem, como havia sido prometido. Se já não é bom ir para a escola e não aprender em período regular, ir para o Apoio Pedagógico - o lugar para os que não aprendem - e permanecer sem aprender é uma duplicação das marcas da figura dos alunos com dificuldades. Marcas que eles não querem para si.

A incapacidade de compreender as dificuldades de aprendizagem dos alunos pode fazer com que os professores inviabilizem as suas tentativas de parecerem com alunos ditos normais: "Joice reclamou que a professora não vê as tarefas dela" (Aparecida). Segundo a mãe, sua filha havia feito a tarefa, mas a professora não olhou seu caderno. A marca da diferença se acentua ainda mais pelo fato de a professora ter olhado o caderno de todos os outros alunos. Se a relação constituída entre professoras e familiares fosse de confiança, Aparecida poderia ter ido até a escola e perguntado porque a professora não viu as tarefas da filha. Porém, não é esse o contexto. Nessas relações de cobrança daquilo que não se pode fazer, não se fala, não se pergunta, apenas fica a frustração e a indignação.

Um dos grandes desejos da escola é a colaboração das famílias para proporcionar a aprendizagem dos filhos. Essa colaboração, quando diz respeito a estudantes em situação de insucesso escolar, normalmente corresponde a fazer aquilo que as professoras não conseguiram fazer: ensiná-los os conteúdos curriculares e ensiná-los a se comportarem como alunos e alunas. A escola busca no modelo de família biparental, heterossexual e de classe média o padrão ideal para oferecer estrutura emocional e econômica que permita a aprendizagem. Aquelas famílias que não se enquadram nesse padrão são consideradas desestruturadas, e por isso não colaboram. Dessa forma, é produzido o discurso da falta que legitima o não aprender: de disponibilidade, de responsabilidade, de interesse, de conhecimento, de vontade, de participação.

Com tanta falta, torna-se quase impossível a escola concluir sua tarefa de ensinar as crianças sem a ajuda dos pais. Para corrigir suas condutas, criam-se espaços de regulação como a Escola de Pais ${ }^{1}$, as reuniões coletivas na escola, as orientações individuais.Esses espaços tornam-se tensos, pois essas famílias não sabem como efetivar aquilo que as escolas lhes exigem como condição de aprendizagem de seus filhos e filhas. Como a escola lhes pede uma coisa que não podem fazer, essas reuniões convocadas se transformam em momentos tensos: "Fico nervosa para 
conversar com a professora"(Aparecida). Nos encontros do grupo, a mãe relata que não vai muito à escola para saber de sua filha, somente comparece quando a chamam por bilhete. Ficava ansiosa por não saber o que a professora iria dizer dela, e ela não sabia qual reação iria ter. Não conseguia questionar a metodologia utilizada pela professora. Relatou muitas vezes que sua filha não entendia o que escreveu e que, por isso, não conseguia fazer a tarefa de casa. Mas não contou isso para a professora, porque ficava muito nervosa nas reuniões. Percebemos, a partir das falas de Aparecida, que a relação que a escola estabelecia com ela era de cobrança. Isso a fazia sentir-se nervosa, impedindo-a de dialogar com a professora; assim, Aparecida apenas ouvia passivamente as queixas da professora em relação à sua filha.

O discurso da inadequação produz a hipótese de uma possível hereditariedade das dificuldades de aprendizagem:"Minha filha é assim porque, quando eu era criança, era igualzinha. E demorei a aprender também" (Gabriela). O que se esconde atrás dessa falsa premissa é que as condições oferecidas pelo sistema de ensino para a sua filha são da mesma natureza precária das que foram oferecidas para Gabriela, escondendo a precariedade do ensino ofertado para as pessoas mais pobres.Esse discurso da individualização das causas do não aprender já subjetivou essa mãe, fazendo com que ela se patologize e patologize sua filha.

Collares e Moyses (1996) também encontraram em suas pesquisas a responsabilização das famílias pelas supostas dificuldades de aprendizagem dos estudantes. Para as autoras, é preciso que a escola conheça os pais, examine, avalie se eles têm condições de colaborar com a escola: "[...] família deve se apresentar à escola. Pois, aparentemente, se o professor não conhecer a mãe, a criança não conseguirá aprender" (COLLARES; MOYSÉS, 1996, p.182). Conhecer a mãe significa conhecer como é a estrutura familiar, como é o seu funcionamento, quais suas condições financeiras, de saúde, de trabalho, de afeto. As professoras acreditam que conhecendo essa estrutura, e buscando faltas nessas existências, podem ter aí uma resposta que justifica a não aprendizagem dos alunos. Conhecendo essas faltas, podem-se operar técnicas de correção que conduzam essas famílias à norma.

Segundo Larrosa (1994), as práticas pedagógicas produzem sujeitos. Não são apenas formas de mediação, mas constituem subjetividades. Para trazer à norma os alunos que não aprendem ou que não se comportam, o dispositivo pedagógico se infiltra nas famílias com o fim de não apenas educar os filhos, mas de governar as famílias.

A busca de informações que permitam produzir verdades e definir condutas configura-se como uma forma de governar essas famílias, com técnicas semelhantes àquelas que Foucault descreve como específicas da polícia europeia do século XVII. No curso Segurança, Território e 
População (2008), o autor descreve essa nova forma de tecnologia que tinha como objetivo conduzir as condutas da população para aumentar as forças do Estado: "O objetivo da polícia é, portanto, o controle e a responsabilidade pela atividade dos homens na medida em que essa atividade possa constituir um elemento diferencial no desenvolvimento das forças do Estado" (FOUCAULT, 2008, p. 433). Essa polícia era composta por um oficial chefe, chamado conservador de polícia, que era responsável por quatros escritórios: Birô de Polícia, de Caridade, de Comércio e de Domínio, todos com o objetivo de regular as condutas da população. Interessa-nos aqui o primeiro Birô, chamado de Polícia, responsável pela instrução das crianças e dos jovens. Além das letras, deveria ensiná-los a caridade, o uso das armas e uma profissão. Ao final de 25 anos, o jovem deveria se apresentar a esse Birô, inscrevendo-se em uma profissão e informando o porquê dessa escolha, seu modo de vida, suas ambições. Se não fizesse isso, não era considerado cidadão. Era tido como vadio e sem honra. Da mesma forma, se hoje as famílias não acatam as orientações da escola, são tidas como desestruturadas e disfuncionais, ameaçando a ordem a e a segurança das cidades.

Mas, para a escola, como é uma família participativa? Para o dispositivo pedagógico, não é somente no início do ano letivo que os pais devem se apresentar à escola. É necessário estar sempre presente aos chamados da instituição, comparecendo às convocações individuais, às reuniões, ser participante e mostrar interesse, questionando sobre a educação (COLLARES; MOYSÉS, 1996). É necessário que a família compareça e que se mostre, se revele, se desnude, para assim a escola conseguir mais elementos para patologizá-las, justificando a queixa escolar por problemas psicológicos ou neurológicos, os quais legitimariam o não aprender, tornando indispensáveis os encaminhamentos.

Quando os alunos demoram a aprender a ler e a escrever, logo surgem as suspeitas e os diagnósticos, que são subjetivados pelos familiares e pelos estudantes, a partir do discurso pedagógico: "A Laura foi à psicóloga, e ela disse que por minha filha não estar aprendendo a ler nem escrever, falaram que ela tem dislexia. Pediram para eu buscar uma pedagoga e profissionais especializados para tratar ela. Pois tudo que ela aprende, logo esquece"(Gabriela). As atividades desenvolvidas ao longo de dois anos no projeto de extensão mostraram uma menina com um bom potencial intelectual, que aprendia rapidamente, mas extremamente insegura quando colocada frente às atividades que exigiam a escrita e a leitura. À medida que essa insegurança foi sendo trabalhada, Laura aprendeu a ler. E gostou.

Collares e Moyses(1996)fazem um levantamento dos supostos problemas de aprendizagem centrados nos alunos: doenças, distúrbios neurológicos, problemas familiares e emocionais. Dentre eles, um dos que mais ganha corpo no discurso pedagógico é a dislexia, uma suposta disfunção 
neurológica que causaria uma incapacidade de processar e significar signos linguísticos, dificultando a proficiência leitora e escritora. No passado, a dislexia já foi nomeada como cegueira verbal e Disfunção Cerebral Mínima. As autoras questionam a grande incidência de estudantes disléxicos, chamando a atenção para a fragilidade e falta de critérios para a realização do diagnóstico. Conceitualmente, o distúrbio da aprendizagem se refere a uma condição biológica essencial ao indivíduo que acaba prejudicando ou impossibilitando a aprendizagem de alguma área especifica, causando uma disfunção neurológica presumível ou comprovada. Juntamente com os diagnósticos, surge um mercado de tratamento, composto pela indústria farmacêutica, pela Medicina e pelas terapias de correção - a fonoterapia, a psicoterapia, a psicopedagogia e a Educação Especial (COLLARES; MOYSÉS, 2013).

Os encaminhamentos de estudantes em situação de insucesso escolar é um fenômeno crescente, que ganha corpo com o surgimento de tratamentos e de medicamentos que corrigiriam disfunções no funcionamento neuroquímico do cérebro, melhorando atenção, concentração e ansiedade: "[...] A administração de medicamentos, a produção de exames e de diagnósticos fazem parte do poder medical, que responde pelos saberes sobre a vida e que está a serviço dos dispositivos pedagógicos" (RATUSNIAK, 2012, p.62).

$\mathrm{O}$ dispositivo pedagógicos e apropria do poder medical, usando os saberes das ciências psi para observar, descrever, diagnosticar e tratar as diferenças, transformando-as em doenças. Para Ramos do Ó (2005, p. 6):

Toda a relação educativa moderna tem uma raiz $p s i$, o que significa que se tornou dependente dos diagnósticos, das orientações teóricas, divisões e formas de explicação que a psicologia concebeu para indexar e reelaborar os imperativos éticos. Pode, então, falar-se de uma regulação psicológica do eu, como derivando daquela ciência da alma em franca expansão há mais de um século. Apontando para as capacidades e as aptidões, a saúde e as doenças, as virtudes e as perversões, a normalidade e as patologias do escolar, a psicologia está na base, de fato, de todas as técnicas e dos dispositivos discursivos relativos à identidade e à conduta. $\mathrm{O}$ arco psicológico não configurou mais que uma problematização sequenciada da forma como as crianças e os jovens foram eles mesmos constituídos historicamente também como um problema.

Laura já passou por duas avaliações de inteligência, com resultados diferentes: a primeira com indícios de superdotação/altas habilidades. A segunda com indícios de deficiência intelectual. No período em que frequentava o projeto, estava aguardando consulta com o neuropediatra, com suspeita de dislexia ou de déficit de atenção. 
A justificativa para o encaminhamento eram seus esquecimentos: "Ela decora a história porque não consegue entender as letrinhas. Às vezes, pega um livrinho e conta a história de sua imaginação [...] A professora disse que ela tem vergonha, que é inteligente. Mas, depois de dez minutos, esquece tudo" (Gabriela). Sem perceber, a mãe vai reproduzindo o discurso que a escola usa para justificar a não aprendizagem da menina: ser esquecida. Esse discurso é tão subjetivante que faz a mãe não perceber que a mesma memória que falta na hora de escrever as palavras sobra na hora de contar a história, como se lapsos na memória pudessem ser tão específicos.

\section{ALGUMAS CONSIDERAÇõeS}

Qual é a justa medida para que a Psicologia não individualize o discurso do fracasso escolar? Somos grandes responsáveis por essa individuação. Foi a Psicologia que produziu as verdades que enquadram os sujeitos em etapas, fases, níveis de desenvolvimento. Foi a Psicologia que produziu a norma e as formas de examinar e avaliar o quanto se está dentro ou fora dela. A forma como o discurso pedagógico capturou esses saberes, permitiu a consolidação da figura do aluno com problemas como descolado das práticas pedagógicas e atrelado a modos de ser específicos de cada um.

Mas a Psicologia também produz saberes que permitem outras verdades. $\mathrm{O}$ avanço das pesquisas na área educacional permitiu que compreendêssemos que a escola é uma instituição de correção e normalização, mas que também pode ser um espaço onde podem existir formas diferentes de ser. Para tanto, é preciso construir espaços de reflexão e de produção de outras nomeações e posições, que permitam outras identidades para essas alunas e esses alunos. É preciso desnaturalizar a individualização das causas do não aprender, problematizando as práticas e produzindo, a partir disso, formas de ensinar que respeitem as diferenças.

Somente por meio de rupturas na cristalização dos preconceitos no cotidiano escolar podemos pensar em deslocamentos que problematizem o fracasso escolar em toda a sua complexidade (COLLARES; MOYSÉS, 1996). Para que todas as crianças aprendam na escola, é preciso criar espaços de problematização sobre o que elas devem aprender, como elas aprendem e qual a melhor forma de ensinar a cada uma delas. Isso é muito mais do que implantar métodos ou técnicas, escolher apostilas, criar dispositivos de reforço pedagógico, encaminhar para especialistas. É considerar a escola um espaço de aprendizagem e de convivência com as diferenças. Dessa forma, será possível aprender a ensinar para cada uma das alunas e cada um dos alunos.

Precisamos produzir estranhamentos sobre os discursos que se produzem acerca dos problemas de aprendizagem, e como nos propõem Lopes e Fabris (2005), 
examinar o que vem sendo dito sobre esse (assim chamado) nãoaprendente. É desses estranhamentos que podem surgir reinvenções. É preciso desmontar o discurso da teoria da carência cultural, da suposta hereditariedade dos problemas de aprendizagem, mostrando que, seo fenômeno do insucesso escolar se repete,é porque as condições (a falta de condições) de ensino se repetem, permanecendo precárias nas escolas oferecidas para os estratos sociais que são mais desprovidos economicamente.

É preciso pensar contra o presente. Pensar diferente, como nos propõe Ramos do Ó (2007). Pensar sobre o lugar que a Psicologia ocupa dentro das tecnologias de governamento da população, regulando psicologicamente aqueles que estão fora da norma e produzindo subjetividades patologizadas. Para sair desse lugar, uma das possibilidades é conhecer melhor o outro, não para capturá-lo e enquadrá-lo, mas para permitir que ele exista, e assim potencializar essa existência. Podemos considerar o projeto de extensão aqui problematizado como um encontro para se conhecer essas alunas, esses alunos e suas famílias. Um encontro que nos permitiu a produção de outros saberes que fortalecem as práticas na Psicologia Escolar.

\section{REFERÊNCIAS}

BRASIL. Lei $\mathrm{n}^{0}$ 9.394, de 20 de dezembro de 1996. Estabelece as diretrizes e bases da educação nacional. Diário Oficial da República Federativa do Brasil, Brasília, DF, 23 dez. 1996. Disponível em: <http://www.planalto.gov.br/ccivil_03/_Ato2011-2014/2014/Lei/L13005. htm>. Acesso em: 13 jan. 2014.

COLLARES, Cecília; MOYSÉS, Maria Aparecida. Preconceitos no cotidiano escolar: ensino e medicalização. São Paulo: Cortez, 1996.

COLLARES, Cecília; MOYSÉS, Maria Aparecida. Medicalização do comportamento e da aprendizagem: consequências para a vida de crianças e adolescentes. Casa em revista, ano III, n. 5, p. 18-29, mar. 2013.

FOUCAULT, Michel. Os anormais. São Paulo: Martins Fontes, 2001.

FOUCAULT, Michel. Segurança, território e população. São Paulo: Martins Fontes, 2008.

FOUCAULT, Michel. Vigiar e punir: nascimento da prisão. Petrópolis: Vozes, 2009.

LARROSA, Jorge. Tecnologias do eu e educação. In: SILVA, Tomaz Tadeu da. O sujeito da educação. Petrópolis: Vozes, 1994. p. 35-86. 
LEANDRINI, Kizzy; SARETTA, Paula. Atendimento em grupo de crianças com queixa escolar: possibilidades de escuta, trocas e novos olhares. In: SOUZA, Beatriz de Paula (Org.). Orientação à queixa escolar. São Paulo: Casa do Psicólogo, 2007. p. 379-398.

LOPES, Maura Corsini; FABRIS, ElíHenn. Dificuldade de aprendizagem: uma invenção moderna. In: ANPED- GT 15 - Educação Especial, 28.,2005, Caxambu. Disponível em <http://28reuniao.anped.org.br/gt15.htm>. Acesso em: 3 ago. 2016.

MALI, Daiane C. Estratégias que a família utiliza para lidar com um filho que apresenta dificuldade de aprendizagem. 2014.41 $\mathrm{f}$. Monografia (Trabalho de Conclusão do Curso de Psicologia) - Universidade do Contestado, Porto União, 2014.

MEDEIROS, Suelin da Cruz. Resultados dos trabalhos realizados em um núcleo de serviço de psicologia de alunos com queixa escolar. 2015. $37 \mathrm{f}$. Monografia (Trabalho de Conclusão do Curso de Psicologia) - Universidade do Contestado, Porto União,2015.

PATTO, Maria Helena Souza. A produção do fracasso escolar: histórias de submissão e rebeldia. São Paulo: Casa do Psicólogo, 1990.

PESSOTTI, Isaias. Deficiência mental: da superstição à ciência. São Paulo: T. A. Queiroz; Editora da Universidade de São Paulo, 1984.

RAMOS DO Ó, Jorge. O governo do aluno na modernidade. Educação - Especial: Foucault pensa a educação, São Paulo: Segmento n. 3, p. 36-45, mar. 2007. Disponível em:<file:///C:/Users/C\%C3\%A9lia/Downloads/Docfoc. com-\%C3\%93,\%20Jorge\%20Ramos\%20do.\%20O\%20governo\%20do\%20aluno\%20na\%2omodernidade\%20(1). pdf>. Acesso em: 3 ago. 2016.

RATUSNIAK, Célia. A história de uns e não de outros: o caderno de ocorrências e a constituição das práticas disciplinares, de controle e de governo das crianças em uma escola pública de anos iniciais. 2012. $167 \mathrm{f}$. Dissertação (Mestrado em em Educação).Universidade Federal de Santa Catarina, Florianópolis, 2012.

SOUZA, Beatriz de Paula. Apresentando a orientação à queixa escolar. In: SOUZA, Beatriz de Paula (Org.). Orientação à queixa escolar. São Paulo: Casa do Psicólogo, 2007a. p. 97-117.

SOUZA. Marilene. Proença. Prontuários revelando os bastidores: do atendimento psicológico à queixa escolar. In: SOUZA, Beatriz de Paula (Org.). Orientação à queixa escolar. São Paulo: Casa do Psicólogo, 2007b. p. 27-58. 
TRAUTWEIN, Carmen. T. G.; NÉBIAS, Cleide. A queixa escolar por quem não se queixa: o aluno. Mental, v. 5, n. 6, p. 123-148. Recuperado de Disponível em: <http://pepsic.bvsalud.org/pdf/mental/v4n6/v4n6a1o. pdf $>$. Acesso em: 14 nov. 2016.

UNIÃO DA VITÓRIA. PME. Plano Municipal de Educação. Lei n. 3.741/2009, de 29 de setembro de 2009. União da Vitória, PR. Mimeografado.

VARELLA, Julia; ALVAREZ-URIA, Fernando. Arqueologia de laescuela. Madrid: La Piqueta, 1991.

VEIGA-NETO, Alfredo. Incluir para excluir. In: LARROSA, Jorge; SKLIAR, Carlos (Org.). Habitantes de Babel, Política e poética da diferença. Belo Horizonte: Autêntica, 2001.

VIANA (2015).

Recebido em: 17/12/2016 Aprovado em: 15/03/2017 